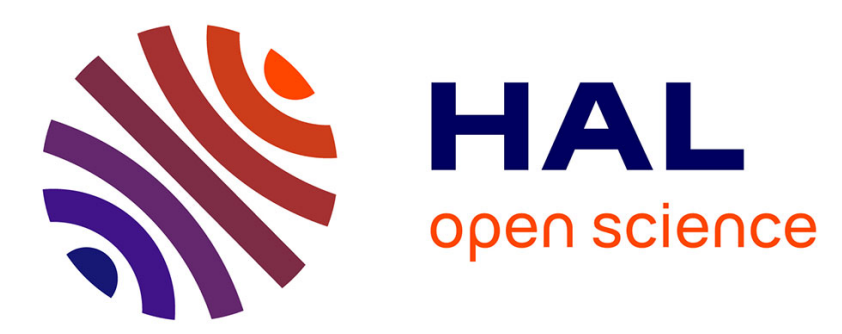

\title{
A Visco-hyperelastic Model With Damage for the Knee Ligaments Under Dynamic Constraints
}

\author{
Pierre-Jean Arnoux, Patrick Chabrand, Michel Jean, Jean Bonnoit
}

\section{To cite this version:}

Pierre-Jean Arnoux, Patrick Chabrand, Michel Jean, Jean Bonnoit. A Visco-hyperelastic Model With Damage for the Knee Ligaments Under Dynamic Constraints. Computer Methods in Biomechanics and Biomedical Engineering, 2002, 5 (2), pp.167-174. 10.1080/10255840290010283 . hal-01648393

\section{HAL Id: hal-01648393 \\ https://hal.science/hal-01648393}

Submitted on 26 Nov 2017

HAL is a multi-disciplinary open access archive for the deposit and dissemination of scientific research documents, whether they are published or not. The documents may come from teaching and research institutions in France or abroad, or from public or private research centers.
L'archive ouverte pluridisciplinaire HAL, est destinée au dépôt et à la diffusion de documents scientifiques de niveau recherche, publiés ou non, émanant des établissements d'enseignement et de recherche français ou étrangers, des laboratoires publics ou privés. 


\title{
A Visco-hyperelastic Model With Damage for the Knee Ligaments Under Dynamic Constraints
}

\author{
P.J. ARNOUX ${ }^{\mathrm{a}, \mathrm{b}, *}$, P. CHABRAND ${ }^{\mathrm{b}}$, M. JEAN ${ }^{\mathrm{b}}$ and J. BONNOIT ${ }^{\mathrm{a}}$ \\ ${ }^{a}$ Laboratoire de Biomécanique Appliquée, URA INRETS, Faculté de Médecine Nord, Université de la Méditerranée, Bd. P. Dramard, 13916 Marseille, \\ cedex 20, France; ${ }^{\mathrm{b}}$ Laboratoire de Mécanique et d'Acoustique, équipe MMC, CNRS, Marseille, France
}

\begin{abstract}
The aim of this study was to identify the behaviour laws governing the knee ligaments, accounting for the damage incurred by the structure under dynamic constraints. The model is developed using a thermodynamic formulation based on the coupling between a viscoelastic model and a damage model. Identification is carried out using the results of dynamic traction tests performed on a bone ligament/bone complex to which traction velocities of around $1.98 \mathrm{~m} / \mathrm{s}$ were applied. The results show the ability of the model to account for the brittle and ductile failure processes occurring in the cruciate and lateral ligaments, respectively.
\end{abstract}

Keywords: Knee ligaments; Viscoelasticity; Damage model; Dynamic constraints

\section{INTRODUCTION}

In automobile accidents and sports injuries, the ligaments of the knee are often subjected to dynamic constraints involving high strain rate, which results in damage or failure of the structure. Both experimental and numerical approaches have been performed to investigate the human behaviour and tolerance in case of impacts and to develop realistic finite element model of the knee. It is therefore necessary to include a damage model in the behaviour laws governing the knee ligaments under dynamic loading. Many advances have been made in characterising the mechanical behaviour of connective tissues, using thermodynamic [1-3], structural [4-7] or phenomenological formulation [8,9]. However, most of the previous models have dealt only with the mechanical behaviour of these tissues under low strain rates or focusing on the elastic response of the structure. Few models for soft tissues taking into account damage were developed [1012]. These models were based on a structural formulation taken into account fibres bundles with different initial lengths and different ultimate forces at failure with, for some authors a statistic distribution of these properties. The aim of the present study was to develop a thermodynamic visco-hyperelastic model with finite transformation damage, by combining a viscoelastic model [3] and a damage model [13]. In the following part, the theoretical basis of the model is presented.
Parametric identification is performed with experimental data obtained on 17 human knee ligaments subjected to dynamic traction in the fibres axes. The experimental measurements are briefly discussed in the second part. The results of the identification procedure are presented in the third part. The last section contains the discussion and the conclusion.

\section{THEORETICAL FORMULATION}

\section{General Principles}

As ligaments are assumed to be submitted to large displacements, the current strain tensor considered, is the Cauchy Green tensor $\left(\mathbf{C}=F^{\prime} F\right)$. The density is assumed to be time independent. The material satisfies the balance conditions (mass and movement conservation) and the two thermodynamics principle [14].

\section{Viscoelastic Constitutive Law}

Based on the local action principle, the principle of material frame-indifference and the principle of fading memory, the stresses occurring in the material can be divided into an elastic stress response, a viscous stress and

\footnotetext{
*Corresponding author.
} 
a long-term memory stress [15].

$$
\begin{aligned}
\mathbf{S}(t)= & S_{\mathrm{e}}(\mathbf{C}(t))+S_{\mathrm{v}}(\dot{\mathbf{C}}(t) ; \mathbf{C}(t))+\int_{\delta}^{\infty} \Sigma\{G(t \\
& -\tau), \tau ; \mathbf{C}(t)\} \mathrm{d} \tau,
\end{aligned}
$$

where $G(t-\tau)=\mathbf{C}(t-\tau)-\mathbf{C}(t)$ describes the space of the strain history, $\Sigma$ is a general tensor-valued function with the variable $G(t-\tau)$ and $\tau$. $\delta$ is a positive real value in the neighbourhood of zero. $\dot{\mathbf{C}}$ is the strain rate tensor. Since the fading memory contribution is negligible compared to the elastic and viscous terms in Eq. (1) and to the damage effects which will be introduced further, the stresses we consider in this study will be reduced to the elastic and viscous contributions.

\section{Free Energy and Viscous Potential}

In the case of an elastic deformation, it has been shown [16] using the second thermodynamic principle, that the elastic contribution $\left(S_{\mathrm{e}}\right)$ to the response of the model can be derivated from a hyperelastic potential.

$$
S_{\mathrm{e}}=2 \rho_{0} \frac{\partial W_{\mathrm{e}}}{\partial \mathbf{C}}
$$

In the same way, the viscous response $\left(S_{\mathrm{v}}\right)$ was introduced using a convex dissipative pseudo potential [16].

$$
S_{\mathrm{v}}=\mathbf{S}-2 \rho_{0} \frac{\partial W_{\mathrm{e}}}{\partial \mathbf{C}}=2 \rho_{0} \frac{\partial W_{\mathrm{v}}}{\partial \dot{\mathbf{C}}}
$$

\section{Isotropy and Incompressibility}

In this work, the ligament is assumed to be homogenous and isotropic. With the representation theorem, the free energy $W_{\mathrm{e}}$ is written as a function of the three invariant of C $\left(I_{1}, I_{2}, I_{3}\right)$.

From Eq. (2), the isotropic stress $S_{\mathrm{e}}$ is obtained by deriving $W_{\mathrm{e}}$ with respect to $\mathbf{C}$ :

$$
S_{\mathrm{e}}=2 \rho_{0}\left[\frac{\partial W_{\mathrm{e}}}{\partial I_{1}} \mathbf{I d}+\frac{\partial W_{\mathrm{e}}}{\partial I_{2}}(\operatorname{tr} \mathbf{C I d}-\mathbf{C})+\frac{\partial W_{\mathrm{e}}}{\partial I_{3}} I_{3} \mathbf{C}^{-1}\right] .
$$

For an incompressible material, the viscoelastic behaviour law of the ligament becomes:

$$
\begin{aligned}
\mathbf{S}= & -p \mathbf{C}^{-1} \\
& +2 \rho_{0}\left[-\frac{\partial W_{\mathrm{e}}}{\partial I_{2}} \mathbf{C}+\frac{\partial W_{\mathrm{v}}}{\partial \dot{\mathbf{C}}}+\left(\frac{\partial W_{\mathrm{e}}}{\partial I_{1}}+\operatorname{tr} \mathbf{C} \frac{\partial W_{\mathrm{e}}}{\partial I_{2}}\right)\right] .
\end{aligned}
$$

\section{Viscoelastic Model With Damage}

Damage evolution law is introduced with a scalar ranging from 0 to 1 and based on a Lemaitre and Chaboche formulation [17,18]. The thermodynamic pairs of variables become $(\mathbf{C}, \mathbf{S})$ and $(D, Y)$, where $Y \in R$ is the thermodynamic force associated with the damage $D$. In this study, damage is assumed to be time independent, not to vary after the ultimate deformation and to affect both the viscous and the elastic properties of the material. The damage energy in the material is written as follows:

$$
W(\mathbf{C}, \dot{\mathbf{C}}, D)=(1-D)\left(W_{\mathrm{e}}+W_{\mathrm{v}}\right)
$$

The associated thermodynamic force $Y(Y \in R)$ is expressed as:

$$
Y=-\frac{\partial W}{\partial D}=W_{\mathrm{e}}+W_{\mathrm{v}} \geq 0 .
$$

The evolution damage law is written using a pseudo potential $\Omega_{D}(Y)$ which is a convex, positive closed function of $Y$. As damage is assumed to be time independent, $\Omega_{D}(Y)$ is replaced by an indicatrice function of a non damage convex, $f_{D}(Y, D) \leq 0$ [13]. With the normality rule, this becomes:

$$
\dot{f}_{D}=\frac{\partial f_{D}}{\partial D} \dot{D}+\frac{\partial f_{D}}{\partial Y} \dot{Y}=0
$$

As $Y$ depends on the left Cauchy Green tensor $\mathbf{C}, \dot{D}$ is expressed by:

$$
\dot{D}=\left\{\begin{array}{ccc}
0 & \text { if } & f_{D}<0 \\
\dot{\delta} \frac{\partial f_{D}}{\partial Y} & \text { if } & f_{D}=0
\end{array}\right.
$$

with

$$
\dot{\delta}=\left\langle>\frac{\frac{\partial f_{D}}{\partial Y} \frac{\partial Y}{\partial \mathbf{C}}: \dot{\mathbf{C}}}{-\frac{\partial f_{D}}{\partial Y} \frac{\partial f_{D}}{\partial D}}\right\rangle, \quad \text { and }\langle\ldots\rangle \quad \text { the positive part. }
$$

\section{Application to the Ligaments}

The parameters of an isotropic incompressible viscoelastic model accounting for damage model of the knee ligaments are calculated on the basis of tensile traction tests with a constant velocity of $1.98 \mathrm{~m} / \mathrm{s}$ in the fibre directions. Considering $l_{0}$ the initial length, $l$ the current length and $v$ the velocity (which is assumed to be constant), the elongation of the ligament is defined by $\lambda=l / l_{0}$ and $l=$ $l_{0}+v t$. The tangent linear application is also given by $F_{i j}=0$ if $i \neq j, F_{11}=\lambda$ and $F_{22}=1 / \sqrt{\lambda}$.

Here the free energy function $W_{\mathrm{e}}$ [19], the viscous pseudo-potential $W_{\mathrm{v}}[20]$ and the damage $f_{D}$ function are expressed, respectively as:

$$
\begin{gathered}
W_{\mathrm{e}}=\alpha \exp \left[\beta\left(I_{1}-3\right)\right]+\gamma\left(I_{2}-3\right), \\
W_{\mathrm{v}}=\frac{\eta}{4} \operatorname{tr}(\dot{\mathbf{C}})^{2}\left(I_{1}-3\right), \\
f_{D}=Y-Q \sqrt[D+D_{0}]{n} \leq 0 .
\end{gathered}
$$


Initially the ligament is assumed to be stress free $\mathbf{S}(\mathbf{I d})=0$. The experimental traction tests were performed without applying any lateral forces to the specimen so that $\mathbf{S}_{22}=0$. Under these conditions, the constitutive equations become after some calculations:

$$
\begin{aligned}
\mathbf{S}_{11}= & -p \frac{1}{\lambda}+(1-D) \eta K \lambda^{2}+2 \alpha \beta(1-D) \\
& \times\left[\exp (\beta K)-\frac{1}{\lambda}\right]
\end{aligned}
$$

with

$$
\begin{aligned}
p= & +2 \alpha \beta \mathbf{C}_{22}(1-D) \exp (\beta K)-\alpha \beta \mathbf{C}_{22}(1-D) \\
& \times\left(\lambda^{2}-\frac{1}{\lambda}\right)-(1-D) \eta K \frac{\dot{\lambda}^{2}}{2 \lambda^{4}}
\end{aligned}
$$

and

$$
\gamma=-\frac{\alpha \beta}{2} \quad \text { and } \quad K=\left(\lambda^{2}+\frac{2}{\lambda}-3\right)
$$

If $f_{D}=0$, then:

$\dot{D}=\frac{n\left(D+D_{0}\right) \dot{\lambda}}{Q \sqrt[D+D_{0}]{n}}\left[-\frac{\alpha \beta}{\lambda}+\alpha \beta \exp \left(\beta\left(\lambda^{2}+\frac{2}{\lambda}-3\right)\right)\right]$

If $f_{D}<0$, then:

$$
\dot{D}=0
$$

The complete viscoelastic model with damage introduced above, is characterised by six parameters, two accounting for the elastic behaviour $(\alpha, \beta)$, one for the viscosity $(\eta)$ and three for the damage $\left(n, Q, D_{0}\right)$. The stress and the hydrostatic pressure are expressed as a function of the time variable and parameters $(\alpha, \beta, \eta, n, Q$, $D_{0}$ ) after analytically integrating the differential Eqs. (16) and (17). Identification of these parameters is performed by minimizing the distance between the simulated and experimental force/displacement curve. Minimization is performed using a conjugate gradient algorithm.

Usually, identification of the viscous component cannot be performed with only one type of experimental test. It is necessary to perform tensile testing with different strain rates or to perform relaxation tests. As we focused on the damage behaviour in the present study, cyclic loading before traction up to failure can damage the material and might therefore affect the mechanical behaviour. One solution to this problem might consist of performing further tensile tests specifically for the purpose of studying the viscous behaviour. Since experimentally the prescribed initial forces have attenuated the viscous effects and since from a numerical point of view the value of $\eta$ did not significantly affect the results, $\eta$ was taken to be small. The behaviour law is written as a relation between the stress and the strain, whereas the identification process is performed on the force displacement relations in order to be in agreement with the experimental measurements. Ligaments are a highly non-homogeneous material in which it is very difficult to determine the deformation and stress because of the ligaments length and section.

\section{Experimental Device}

Identification was performed with the knee ligaments of four human donors obtained from the Faculty of Medicine of the Mediterranean University (Marseille, France). All the knee cadavers were treated using Winckler's conservation solution and refrigerated at $+3{ }^{\circ} \mathrm{C}$ [21]. The dissection consisted in removing a bone/ligament/bone complex with each ligament. The biometry consisted in evaluating the length, section (in the middle and at the two insertion points) and relative orientation of the ligaments insertions surfaces before and after removal. According to the study [22], the ligaments were assumed to have elliptic sections. The bone insertions were embedded with resin in the spherical part. The sample was fixed in a specially designed apparatus (Fig. 1) to perform tensile traction tests in the direction of the fibre axes with velocities of $1.98 \mathrm{~m} / \mathrm{s}$ up to the failure of the structure. The special feature of this apparatus [23] is that it can be used to perform dynamic tensile traction tests (using a hydraulic Schenck jack) in all the possible relative orientations of the ligaments (corresponding to the anatomical axes or other). The tests were carried out at room temperature (around $23^{\circ} \mathrm{C}$ ), and a pre-load comprised between 5 and $25 \mathrm{~N}$ was applied to each ligament prior to each test. In

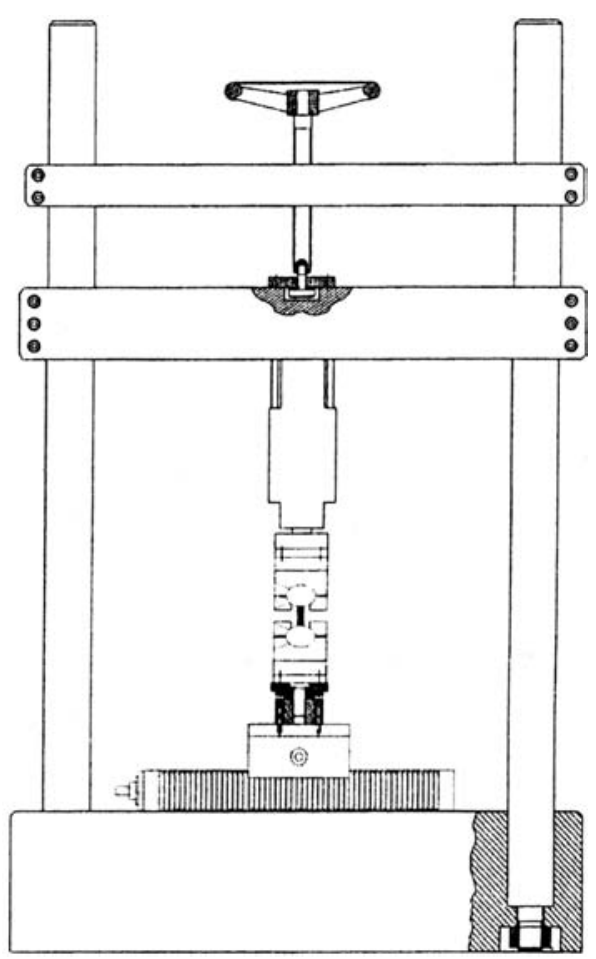

FIGURE 1 The experimental device. 


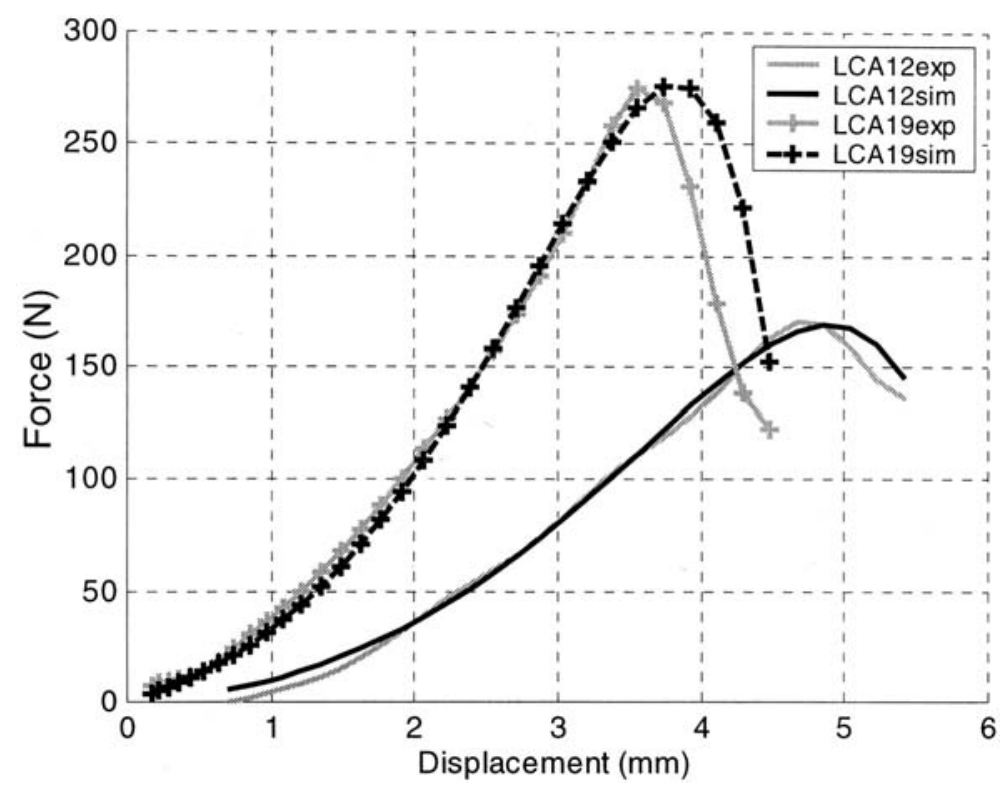

FIGURE 2 Identification of the behaviour in the case of two anterior cruciate ligaments 12 (LCA12) and 19 (LCA19).

order to keep the ligament sufficiently moist, Winckler solution was regularly applied. Measurements were performed with a 3D Kistler force transducer, an accelerometer and a displacement transducer. Data acquisition were performed at a sampling frequency of $10 \mathrm{kHz}$ and corrected using a $1 \mathrm{kHz}$ filter.

\section{RESULTS}

The force versus displacement obtained curves plotted (Figs. 2-5) can be divided into three parts.

First they contain a non linear elastic region with a low modulus, which was negligible because of the force initially applied. Secondly an elastic linear region for which Young's modulus can be calculated, and lastly damage region up to failure. The damage phase of cruciate ligaments is very brittle, occurs at deformation levels of around $18 \%$ (in the case of equally pre-stressed ligaments), and consists of the two-stage failure of the two main fibres. With lateral ligaments, this phenomenon is more ductile, occurs at deformation levels of around $24 \%$, and involves the failure of only one bundle of fibres.

Parameters of the behaviour law were identified on each ligaments. These parameters were determinate considering the whole behaviour for lateral ligaments and considering only the first damage step for cruciates ligaments. For these results, comparisons between the average error observed between the simulated and experimental behaviour showed that the error with parametric identification was less than $8 \%$ for all the ligaments. In regard of the pre-stress applied, the viscous part of the model has not a sensible influence on its response. Nevertheless, it could be considered as a mean of regularising the behaviour at the end of the elastic phase.

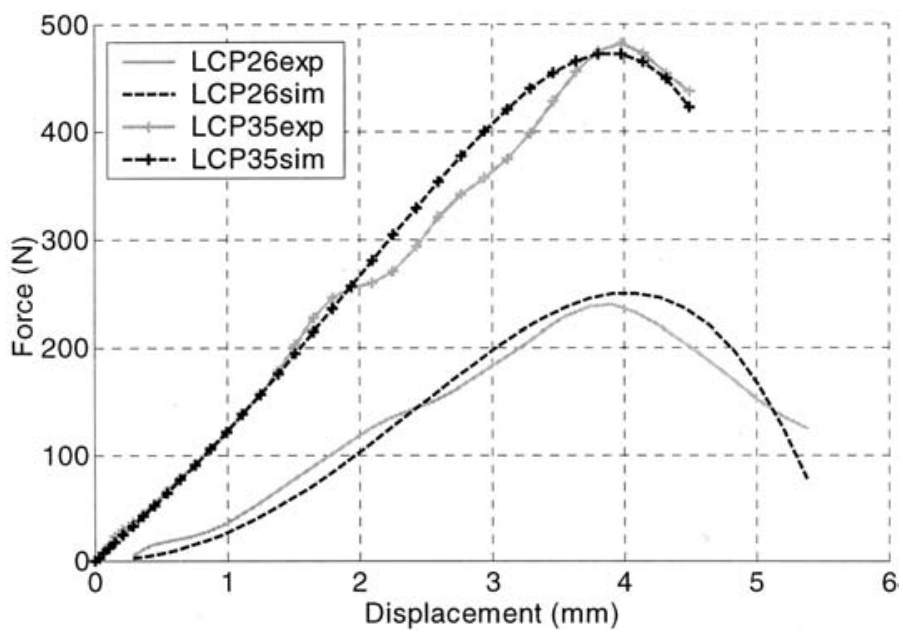

FIGURE 3 Identification of the behaviour of two posterior cruciate ligaments 26 (LCP26) and 35 (LCP35). 


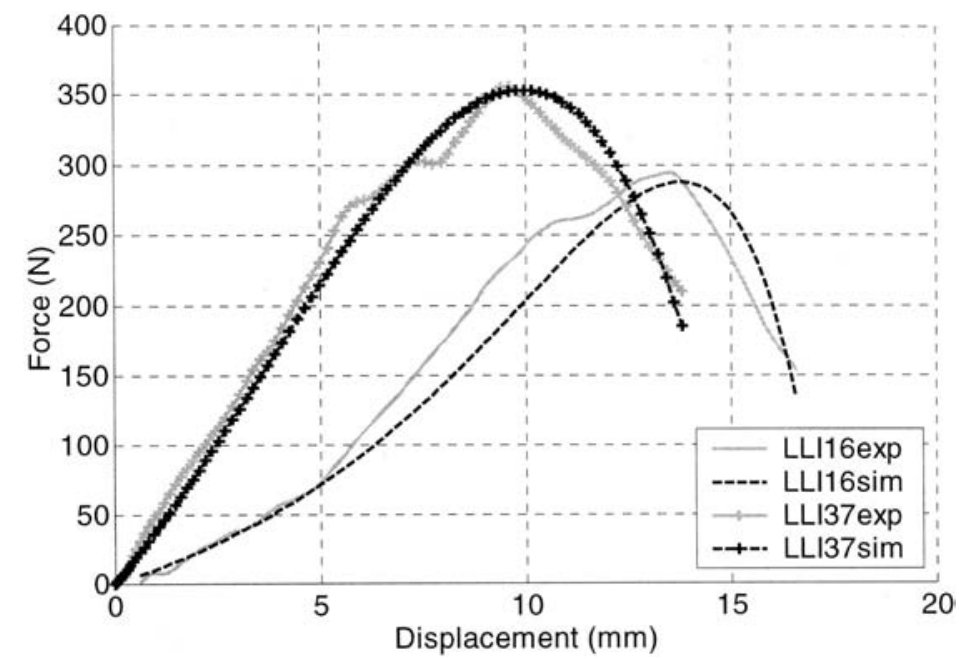

FIGURE 4 Identification of the behaviour of two medial collateral ligaments 16 (LLI16) and 37 (LLI37).

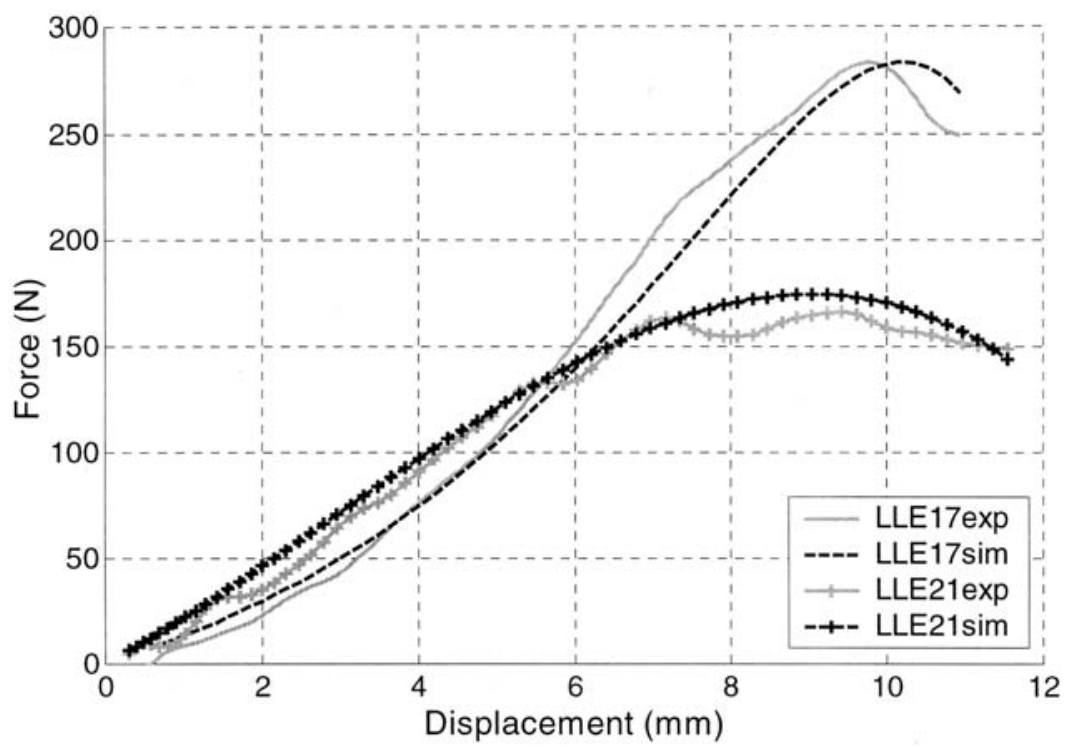

FIGURE 5 Identification of the behaviour of two fibular collateral ligaments 17 (LLE17) and 21 (LLE21).

TABLE I Characteristics of ligaments LCA12 and LCA19

\begin{tabular}{lcccccrrrr}
\hline Ligament & $S\left(\mathrm{~mm}^{2}\right)$ & $I_{0}(\mathrm{~mm})$ & $\alpha$ & $\beta$ & $\eta$ & $D_{0}$ & $Q$ & $n$ & Error $(N)$ \\
\hline LCA12 & 50 & 19 & 0.223 & 7.341 & $1.5 \times 10^{-5}$ & 0.755 & 199.99 & 1 & 3.79 \\
LCA19 & 43 & 20 & 0.480 & 10.863 & $1.35 \times 10^{-5}$ & 0.429 & 164.97 & 1 & 11.06 \\
\hline
\end{tabular}

TABLE II Characteristics of ligaments LCP26 and LCP35

\begin{tabular}{lcccccccc}
\hline Ligament & $s\left(\mathrm{~mm}^{2}\right)$ & $I_{0}(\mathrm{~mm})$ & $\alpha$ & $\beta$ & $\eta$ & $D_{0}$ & $Q$ & $n$ \\
\hline LCA26 & 55 & 21 & 1.671 & 3.738 & 0.2 & 0.99 & 4.54 & 1 \\
LCA35 & 55.1 & 26 & 5.09 & 3.84 & $3.8 \times 10^{-6}$ & 0.1 & 77.3 & 1 \\
\hline
\end{tabular}


TABLE III Characteristics of ligaments LLI16 and LLI37

\begin{tabular}{lccccccccc}
\hline Ligament & $S\left(\mathrm{~mm}^{2}\right)$ & $I_{0}(\mathrm{~mm})$ & $\alpha$ & $\beta$ & $\eta$ & $D_{0}$ & $Q$ & $n$ & Error $(N)$ \\
\hline LLI16 & 85 & 35 & 0.838 & 2.061 & $2.8 \times 10^{-7}$ & 0.20 & 93.85 & 1 & 16.18 \\
LLI37 & 81.4 & 32 & 31.13 & 0.165 & $7.6 \times 10^{-7}$ & 0.07 & 33.69 & 1 & 11.74 \\
\hline
\end{tabular}

TABLE IV Characteristics of ligaments LLE17 and LLE21

\begin{tabular}{|c|c|c|c|c|c|c|c|c|c|}
\hline Ligament & $s\left(\mathrm{~mm}^{2}\right)$ & $I_{0}(\mathrm{~mm})$ & $\alpha$ & $\beta$ & $\eta$ & $D_{0}$ & $Q$ & $n$ & Error $(N)$ \\
\hline LLE17 & 82 & 35 & 0.959 & 1.301 & $5.2 \times 10^{-8}$ & 0.0001 & 45.29 & 1 & 9.18 \\
\hline LLE21 & 62.8 & 19 & 2847 & 0.002 & $2.5 \times 10^{-7}$ & 0.703 & 153.65 & 1 & 6.65 \\
\hline
\end{tabular}

Comparison between numerical and experimental response of the ligaments to dynamic tensile loading is presented in Figs. 3-5. A summary of the ligaments properties, biometry and parameters of the behaviour law obtained on each ligament was presented in Tables I-IV.

\section{DISCUSSION}

In this study, a thermodynamical formulation is used to describe the behaviour law governing knee ligaments. The model obtained accounts differently for the mechanical behaviour, depending on whether it is hyperelastic, viscoelastic or viscoelastic with damage. The structure is assumed to be isotropic and the results obtained with the model, which is written using finite transformation are in good agreement with the already published results [2325]. The damage components is able to take into account for the variability of the behaviour observed at the occurrence of brittle and ductile failure in the cruciate and lateral ligaments, respectively.

\section{On the Model Hypothesis}

The ligaments are assumed to be isotropic because of the directions in which the loading occurs. Transverse isotropy would be an interesting possibility, but it would be very difficult to determine the response of the structure under transverse loading conditions. The material is assumed to be initially stress-free, which is equivalent to making a change of variable in the stress. $\mathbf{S}_{22}$ is assumed to be zero, which was checked experimentally. Materials of this kind have generally been assumed to be incompressible [22], in view of their high water content (water accounts for more than $80 \%$ of the total constituents).

\section{On the Thermodynamic Potential}

The elastic potential used in this study is well adapted to the context of finite transformations. Although Fung (1993) or Pioletti (1997) have established the existence of a direct correlation between $\alpha, \beta$ and the material characteristics, no correlations were tested in this study. In the identification of the parameters, no particular attention was paid to which of the solutions of the minimization problem should be chosen. It would be worth carrying out further studies on the choice of the most physically reliable solution of the minimization problem.

Short memory effects are described via the viscous pseudo potential, which is advantageous in that it entails viewing the strain rate as an explicit variable, and the short term memory effects are characterized with an independent parameter $\eta$. With the high strain rate applied to the ligaments in the present study, the viscous effects are small, which is numerically checked with $\eta$ values. However, the short-term memory has regularising effects at the end of the elastic phases. In our experimental campaign the number of specimens available to be tested, was not sufficient to perform a complete identification of $\eta$. For such an identification cyclic or relaxation loadings prior to the traction up to failure are necessary, these are liable to damage the structure as well as affecting its properties. As we were limited here by the number of samples available, we decided not to risk altering the structure.

Damage laws give a good description of damage processes, except in the case of the cruciate ligaments, in which only the first bundle of fibres is subject to failure. In this study, all the ligaments were tested with the same velocity, which made it difficult to determine its effects.

Further studies require to be performed at various velocities in order to determine the time dependence. The indicatrice function giving the nondamage convex depends only on the elastic component. This shows that the damage is not time dependent and cannot evolve any further after the ultimate strain. The damage is controlled here using the damage yield $D_{0}$, the intensity of the damage $Q$ and the linearity parameter $n$ (which is fixed and taken to equal one). These parameters are not directly associated with the physics of the structure. In further studies, the physics of the evolution law damage variables might be investigated by developing a structural model for the ligaments.

In order to complete the identification of the viscous parameters and the description of the damage in the structure, further experiments now require to be carried out with various strain rates. 


\section{On the Identification Algorithm}

Fitting the parameters requires minimizing the distance between the simulated and experimental responses. This optimisation is performed with a conjugate gradient algorithm, using quadratic estimation on the central derivative. The relative accuracy and convergence criteria amount were $10^{-5}$ and $10^{-3}$, respectively, with a maximum number of iterations of less than 150 . The average error obtained with all the ligaments did not exceed $8 \%$ of the maximum force. Although this algorithm gives good results, each set of parameters is the first local minimum in the identification process.

\section{CONCLUSION}

The present thermodynamic approach, which was based on an extension of the Pioletti model to large displacements with high strain rates, combined with a damage model [13], was found to satisfactorily describe the failure process at work in the cruciate and lateral knee ligaments. In this model, there is no correlation between the parameters $\left(\alpha, \beta, \eta, n, Q, D_{0}\right)$ and the physics or the measurements performed during the experimental testing. It would be interesting to attempt in the future to find a relation between the parameters and physical principles governing the behaviour of the material. In this case, the model would have to take the anisotropy of the material into account. Other experiments will also be required to determine the time dependence of the damage evolution law.

\section{NOMENCLATURE}

$\begin{array}{ll}\mathbf{S} & \text { second stress Piola Kirschoff tensor } \\ \mathbf{C} & \text { Cauchy Green strain tensor } \\ \mathbf{C} . & \text { Strain rate tensor } \\ t & \text { time } \\ \rho_{0} & \text { density } \\ W_{\mathrm{e}} & \text { specific free energy } \\ W_{\mathrm{v}} & \text { viscous pseudo potential } \\ \mathbf{I d} & \text { identity tensor } \\ I_{1}, I_{2}, I_{3} & \text { the three invariants of the Cauchy Green } \\ \alpha, \beta, \gamma & \text { tensor } \\ \eta & \text { free energy parameters } \\ p & \text { viscous parameter } \\ D & \text { hydrostatic pressure } \\ \dot{D} & \text { damage } \\ Y & \text { damage rate } \\ & \text { thermodynamic force associated with the } \\ D_{0} & \text { damage } \\ Q & \text { non damage yield } \\ & \text { parameters contributing to the intensity of } \\ & \text { the damage }\end{array}$

\begin{tabular}{|c|c|}
\hline$n$ & linearity of the damage evolution \\
\hline$\lambda$ & elongation \\
\hline$l_{0}$ & initial length \\
\hline$l$ & actual length \\
\hline$s$ & section \\
\hline$V=1.98 \mathrm{~m} / \mathrm{s}$ & velocity \\
\hline $\operatorname{tr}$ & trace operator \\
\hline$S_{\mathrm{e}}$ & Elastic stress contribution \\
\hline$S_{\mathrm{v}}$ & $\begin{array}{l}\text { Viscous stress contribution (short memory } \\
\text { effects) }\end{array}$ \\
\hline$f_{D}$ & $\begin{array}{l}\text { indicatrice function of a non damage } \\
\text { convex }\end{array}$ \\
\hline$f_{D}$ & $\begin{array}{l}\text { time derivative of the indicatrice function } \\
\text { of a non damage convex }\end{array}$ \\
\hline$R$ & Set of real numbers \\
\hline
\end{tabular}

\section{References}

[1] Dehoff, H. (1978) "On the non linear viscoelastic behaviour of soft biological tissues", J. Biomech. 11, 35-40.

[2] Bingham, D.N. and Dehoff, P.H. (1979) "A constitutive equation for the canine anterior cruciate ligament", J. Biomech. Eng. 101, $15-22$.

[3] Pioletti, D.P., "Viscoelastic Properties of Soft Tissues: Application to knee ligament and tendon", PhD Thesis, Lausanne, EPFL (Switzerland).

[4] Lanir, Y. (1980) "A microstructure model for the rheology of mammalian tendon", J. Biomech. Eng. 102, 332-339.

[5] Maes, M., Vanhuyse, V., Decraemer, W. and Raman, E. (1989) “A thermodynamically consistent constitutive equation for the elastic force-length relation of soft biological materials", J. Biomech. 22(11/12), 1203-1208.

[6] Sasaki, N. and Odajima, S. (1996) "Strain-stress curve and Young's modulus of a collagen molecule as determined by the X-ray diffraction technique", J. Biomech. 29(5), 655-658.

[7] Sasaki, N. and Odajima, S. (1996) "Elongation mechanism of collagen fibrils and force strain relations of tendon at each level of structural hierarchy", J. Biomech. 29(9), 1131-1136.

[8] Fung, Y.C. (1973) "Biorheology of soft tissues", Biorheology 10, $139-155$.

[9] Viidik, A. (1973) "Functional properties of collagenous tissues", International Reviews of Connective Tissue Research (Academic Press, New York) 6.

[10] Kwan, M. and Woo, S. (1989) "Technical brief: a structural model to describe the nonlinear stress-strain behaviour for parallel-fibered collagenous tissues", J. Biomech. Eng. 111/361, 361-363.

[11] Hurschler, C., Loitz-Ramage, B. and Vanderby, R. (1997) "A structurally based stress stretch relationship for tendon and ligament", J. Biomech. Eng. 119, 392-399.

[12] Liao, H. and Belkoff, S. (1999) "A failure model for ligaments", J. Biomech. 32, 183-188.

[13] Andrieux, F., "Sur les milieux visco-hyperelastiques endommageables", PhD Thesis, Université de Technologie de Compiègne (France).

[14] Malvern, L.E. (1969) Introduction to: The Mechanics of a Continuous Medium (Prentice Hall, Englewood Cliffs, NJ).

[15] Pioletti, D.P. and Rakotomanana, L.R. (2000) "Non linear viscoelastic law for soft biological tissues", Eur. J. Mech. 5, 749-759.

[16] Germain, P. (1986) Cours de mécanique des milieux continus. T. (Masson, Paris), pp 1-2.

[17] Kachanov, L.M. (1958) "Time of the rupture process under creep conditions", Z. W. Akad. Nauk., S. S. R.

[18] Chaboche, J.L. (1987) "Continuum damage mechanics, part I: general concepts”, J. Appl. Mech. 55, 59-64.

[19] Demiray, H. (1972) "A note on the elasticity of soft biological tissues", J. Biomech. 5, 309-311.

[20] Pioletti, D.P., Rakotomanana, L.R., Benvenuti, J.F. and Leyvraz, P.F. (1998) "Viscoelastic constitutive law in large deformations: application to the knee ligaments and tendons", J. Biomech. 31, $753-757$. 
[21] Winckler, G. (1974) Manuel d'Anatomie Topographique et Fonctionnelle, 2nd Ed. (Masson, Paris).

[22] Noyes, F.R. and Grood, E.S. (1976) "The strength of the anterior cruciate ligament in humans and rhesus monkeys", J. Bone Joint Surg. 58A, 1074-1081.
[23] Arnoux, P.J., "Modélisation des ligaments des membres porteurs", PhD Thesis, Université de la Méditerranée (France).

[24] Viidik, A. (1980) "Mechanical properties of parallel-fibred collagenous tissues", Proc. Symp. Biol. Collagen, 237-255.

[25] Fung, Y.C. (1993) Biomechanics. Mechanical Properties of Living Tissues (Springer, Berlin). 